\title{
Metformin use and respiratory outcomes in asthma-COPD overlap
}

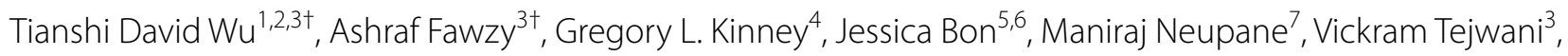
Nadia N. Hansel ${ }^{3}$, Robert A. Wise ${ }^{3}$, Nirupama Putcha ${ }^{3}$ and Meredith C. McCormack ${ }^{3 *}$ (D)

\begin{abstract}
Background: Metformin is associated with improved respiratory outcomes in asthma; however, metformin in COPD and asthma-COPD overlap (ACO) remains unexplored.

Objective: To determine the association between metformin use and respiratory outcomes in COPD and ACO.

Study design and methods: Participants with COPD (FEV1/FVC $<0.70)$ in the Genetic Epidemiology of COPD study (COPDGene ${ }^{\circledR}$ ) were categorized as ACO $(n=510)$, defined as concurrent physician-diagnosed asthma before age 40 years, or COPD alone $(n=3459)$. We estimated the association of baseline metformin use with (1) rate of total and severe respiratory exacerbations during follow-up, (2) cross-sectional St. George's Respiratory Questionnaire (SGRQ) score, six-minute walk distance (6MWD), and post-bronchodilator FEV1 percent predicted (FEV1 pp), and (3) 5-year change in SGRQ, 6MWD, and FEV1 pp. We also examined change in SGRQ, 6MWD and FEV1 pp among participants who initiated metformin during follow-up $(n=108)$ compared to persistent metformin non-users $(n=2080)$. Analyses were adjusted for sociodemographic factors, medications, and comorbidities.

Results: Among participants with ACO, metformin use was associated with lower rate of total (adjusted incidence rate ratio [aIRR] 0.3; 95\% confidence interval $[95 \% \mathrm{Cl}] 0.11,0.77$ ) and severe exacerbations (alRR $0.29 ; 95 \% \mathrm{Cl} 0.10,0.89$ ). Among participants with COPD alone, there was no association between metformin use with total (aIRR 0.98; $95 \% \mathrm{Cl}$ $0.62,1.5$ ) or severe exacerbations (aIRR 1.3; 95\% Cl 0.68, 2.4) (p-interaction < 0.05). Metformin use was associated with lower baseline SGRQ score (adjusted mean difference [aMD] - 2.7; 95\%Cl $-5.3,-0.2$ ) overall. Metformin initiation was associated with improved SGRQ score (aMD -10.0; $95 \% \mathrm{Cl}-18.7,-1.2)$ among participants with ACO but not COPD alone (p-interaction $<0.05$ ). There was no association between metformin use and 6MWD or FEV1 pp in any comparison.
\end{abstract}

Conclusions: Metformin use was associated with fewer respiratory exacerbations and improved quality of life among individuals with ACO but not COPD alone. Results suggest a potential role for metformin in ACO which requires further prospective study.

Trial Registry: NCT00608764

Keywords: Asthma-COPD overlap, Exacerbations, Metformin

*Correspondence: mmccor16@jhmi.edu

${ }^{\dagger}$ Tianshi David Wu and Ashraf Fawzy contributed equally to this work

${ }^{3}$ Division of Pulmonary and Critical Care Medicine, Johns Hopkins School of Medicine, 1830 E. Monument St. 5th Floor, Baltimore, MD 21205, USA

Full list of author information is available at the end of the article

\section{Background}

Individuals with asthma-COPD overlap (ACO) share clinical and physiologic features of both asthma and COPD [1]. While there is inconsistency regarding its diagnostic criteria and disagreement on whether it represents a distinct condition, it is clear that these individuals original author(s) and the source, provide a link to the Creative Commons licence, and indicate if changes were made. The images or other third party material in this article are included in the article's Creative Commons licence, unless indicated otherwise in a credit line to the material. If material is not included in the article's Creative Commons licence and your intended use is not permitted by statutory regulation or exceeds the permitted use, you will need to obtain permission directly from the copyright holder. To view a copy of this licence, visit http://creativecommons.org/licenses/by/4.0/. The Creative Commons Public Domain Dedication waiver (http://creativeco mmons.org/publicdomain/zero/1.0/) applies to the data made available in this article, unless otherwise stated in a credit line to the data. 
are especially vulnerable to poor health outcomes and experience greater morbidity than individuals with COPD alone [2, 3]. Because medication trials for asthma and COPD have generally excluded individuals with the opposing condition, evidence-based treatments for ACO remain sparse [4].

Metformin is an oral medication that is commonly indicated for the treatment of type 2 diabetes. In translational and epidemiologic studies of asthma, metformin has been associated with diminished allergic airway inflammation [5] and lower risk of disease exacerbation [6]. However, in studies of COPD, metformin did not reduce risk of hyperglycemia or risk of re-hospitalization for COPD [7]. Further, a study of Taiwan's National Health Insurance Program reported a higher risk of pneumonia and hospitalization for COPD among metformin users [8]. These contrasting reports create uncertainty with respect to potential effects of metformin in both COPD and ACO.

Consequently, we sought to determine (1) the association of metformin use and respiratory outcomes among individuals with $\mathrm{ACO}$ and (2) whether these associations differ between $\mathrm{ACO}$ and COPD alone. We hypothesize that metformin use would be associated with lower risk of respiratory morbidity preferentially among individuals with ACO.

\section{Study design and methods Cohort description}

The Genetic Epidemiology of COPD (COPDGene) study is an ongoing multi-center observational study with the goal of identifying genetic factors associated with COPD comprised of self-identified non-Hispanic whites or African-Americans aged $45-80$ years with $\geq 10$ pack-year smoking history. Full study details are reported elsewhere [9]. Participants underwent in-person characterization at baseline (phase 1) and year five (phase 2) in addition to telephone or web-based follow-ups at 3- to 6-month intervals. The current analysis includes follow-up data current as of July 31, 2018.

The analytic cohort was defined as participants with COPD, defined as FEV1/FVC $<0.70$, who provided medication data at baseline and contributed follow-up data. Participants with ACO were defined as those with COPD and a diagnosis of asthma by a physician before the age of 40 years [10]. In sensitivity analyses, we also tested asthma diagnosed by a physician at any age and selfreported asthma not requiring a physician diagnosis.

\section{Exposure definitions}

Metformin use was extracted from participant reported medication inventories obtained at baseline and 5-year follow-up (Additional file 1: Table S1). Medication tables were manually reviewed for misspellings and brand names of metformin to minimize misclassification. For the main analysis, the comparison was between participants who reported metformin use versus no metformin use at baseline.

We also investigated changes in respiratory outcomes associated with initiation of metformin. A metformin initiator was defined as a participant who reported no metformin use at baseline but metformin use at 5-year follow-up. In this analysis, the comparison was between initiators of metformin versus participants who reported no metformin use at baseline and follow-up.

\section{Outcome and covariate definitions}

The primary outcome was the rate of total and severe respiratory exacerbations. Using automated telephone calls and web-based data entry, participants were asked to quantify the number of exacerbations and the outcome of each event at 3 to 6 month intervals. Severe exacerbations were flares that resulted in emergency department visit or hospitalization. Total exacerbations include severe exacerbations and exacerbations that resulted in an antibiotic or corticosteroid prescription.

Medication use and sociodemographic factors were assessed by questionnaire. Quality of life was assessed by the St. George Respiratory Questionnaire (SGRQ) score [11], which ranges from 0 to 100, with higher scores reflecting worse impact. The minimal clinically important difference (MCID) in asthma and COPD is 4 [12]. Functional ability was assessed by the 6-min walk distance (6MWD) which has a MCID of 90 feet in COPD [13]. Post-bronchodilator spirometry was performed in accordance with American Thoracic Society guidelines, and predicted values were calculated [14], from which post-bronchodilator $\mathrm{FEV}_{1}$ percent predicted $\left(\mathrm{FEV}_{1} \mathrm{pp}\right)$ was extracted.

\section{Analytic approach}

The association of metformin use and rate of total and severe respiratory exacerbations was estimated by a negative binomial model with years of follow-up as an offset. Cross-sectional associations of metformin use with SGRQ, 6MWD, and FEV1pp at baseline were estimated by linear regression.

Differences in the change of SGRQ score, 6MWD, and FEV1pp associated with prevalent and incident metformin use between baseline and follow-up were estimated by linear mixed models, accounting for repeated measurements within participant using an unstructured covariance, with random intercept by center. The difference attributable to metformin was represented by a metformin-time interaction. 
All models were adjusted for age, sex, race, education (less than high school, high school or greater), smoking status (current, former), body mass index (BMI; underweight, normal or overweight, obese), inhaled corticosteroid use, oral corticosteroid use, other diabetes medication use, $\mathrm{FEV}_{1} \mathrm{pp}$, and a comorbidity count [15]. Exacerbation models and cross-sectional models of SGRQ, 6MWD and FEV1pp were additionally adjusted for respiratory exacerbation in the prior year (yes, no). $\mathrm{FEV}_{1} \mathrm{pp}$ was not included for estimates of $\mathrm{FEV}_{1} \mathrm{pp}$ as an outcome. In longitudinal models of prevalent metformin use, smoking status, BMI, and $\mathrm{FEV}_{1}$ pp were included as time-varying covariates. Time-varying inhaled and oral corticosteroid use were also included in longitudinal models of incident metformin use.

Interaction by the presence or absence of $\mathrm{ACO}$ was tested and stratified estimates were produced. A twosided p-value $<0.05$ was accepted as statistically significant. All analyses were performed in SAS 9.4 (Cary, NC).

\section{Regulatory statement}

COPDGene is performed with local IRB authorization from participating centers and is registered at ClinicalTrials.gov (NCT00608764). All study participants provided written informed consent.

\section{Results \\ Cohort description}

From the initial cohort, 3969 individuals with COPD who had complete baseline medication data and accrued follow-up time were identified (Additional file 1: Figure S1). Mean (SD) participant age was 63.6 (8.5) and $45 \%$ identified as female (Table 1). Participants who used metformin were older, had a greater number of comorbidities and lower proportion of females, and were less likely to be currently smoking. Of this group, 510 (13\%) reported a diagnosis of asthma made by a physician before the age of 40 and were thus classified as ACO. On average, participants with ACO were younger, more commonly

Table 1 Baseline characteristics of included participants by baseline metformin use $(n=3969)$

\begin{tabular}{|c|c|c|c|}
\hline Characteristic [N (\%) or Mean \pm SD] & Metformin Non-Users $(n=3728)$ & Metformin Users $(n=241)$ & p-value \\
\hline Age & $63.4 \pm 8.5$ & $65.7 \pm 7.5$ & $<0.01$ \\
\hline Female gender & $1703(46)$ & $82(34)$ & $<0.01$ \\
\hline Black race & $747(20)$ & $43(18)$ & 0.4 \\
\hline \multicolumn{4}{|l|}{ GOLD stage } \\
\hline GOLD 1 & $650(17)$ & $34(14)$ & \\
\hline GOLD 2 & $1602(43)$ & $107(44)$ & 0.2 \\
\hline GOLD 3 & $980(26)$ & $75(31)$ & \\
\hline GOLD 4 & $496(13)$ & $25(10)$ & \\
\hline Post-bronchodilator FEV1pp & $57.3 \pm 22.7$ & $56.5 \pm 20.7$ & 0.6 \\
\hline Current smoker & $1513(41)$ & $72(30)$ & $<0.01$ \\
\hline \multicolumn{4}{|l|}{ Body mass index } \\
\hline Underweight & $103(3)$ & $1(1)$ & \\
\hline Normal/overweight & $2508(67)$ & $94(39)$ & $<0.01$ \\
\hline Obese & $1117(30)$ & $146(61)$ & \\
\hline Exacerbation in prior year & $1266(34)$ & $97(40)$ & 0.05 \\
\hline Physician-diagnosed asthma & $818(22)$ & $59(25)$ & 0.4 \\
\hline Before age 40 & $471(13)$ & $39(16)$ & 0.1 \\
\hline \multicolumn{4}{|l|}{ Medications } \\
\hline Inhaled corticosteroids & $390(11)$ & $27(12)$ & 0.7 \\
\hline Oral corticosteroids & $165(5)$ & $10(4)$ & 0.9 \\
\hline Insulin & $18(1)$ & $5(2)$ & 0.01 \\
\hline Other diabetes medication & $83(2)$ & $103(43)$ & $<0.01$ \\
\hline \multicolumn{4}{|l|}{ Comorbidities } \\
\hline Comorbidity count & $2.3 \pm 1.7$ & $4.1 \pm 1.7$ & $<0.01$ \\
\hline Coronary artery disease & $327(9)$ & $48(20)$ & $<0.01$ \\
\hline Congestive heart failure & $153(4)$ & $18(8)$ & 0.01 \\
\hline Stroke & $125(3)$ & $10(4)$ & 0.5 \\
\hline Hypertension & $1735(47)$ & $179(74)$ & $<0.01$ \\
\hline High cholesterol & $1522(41)$ & $171(71)$ & $<0.01$ \\
\hline
\end{tabular}




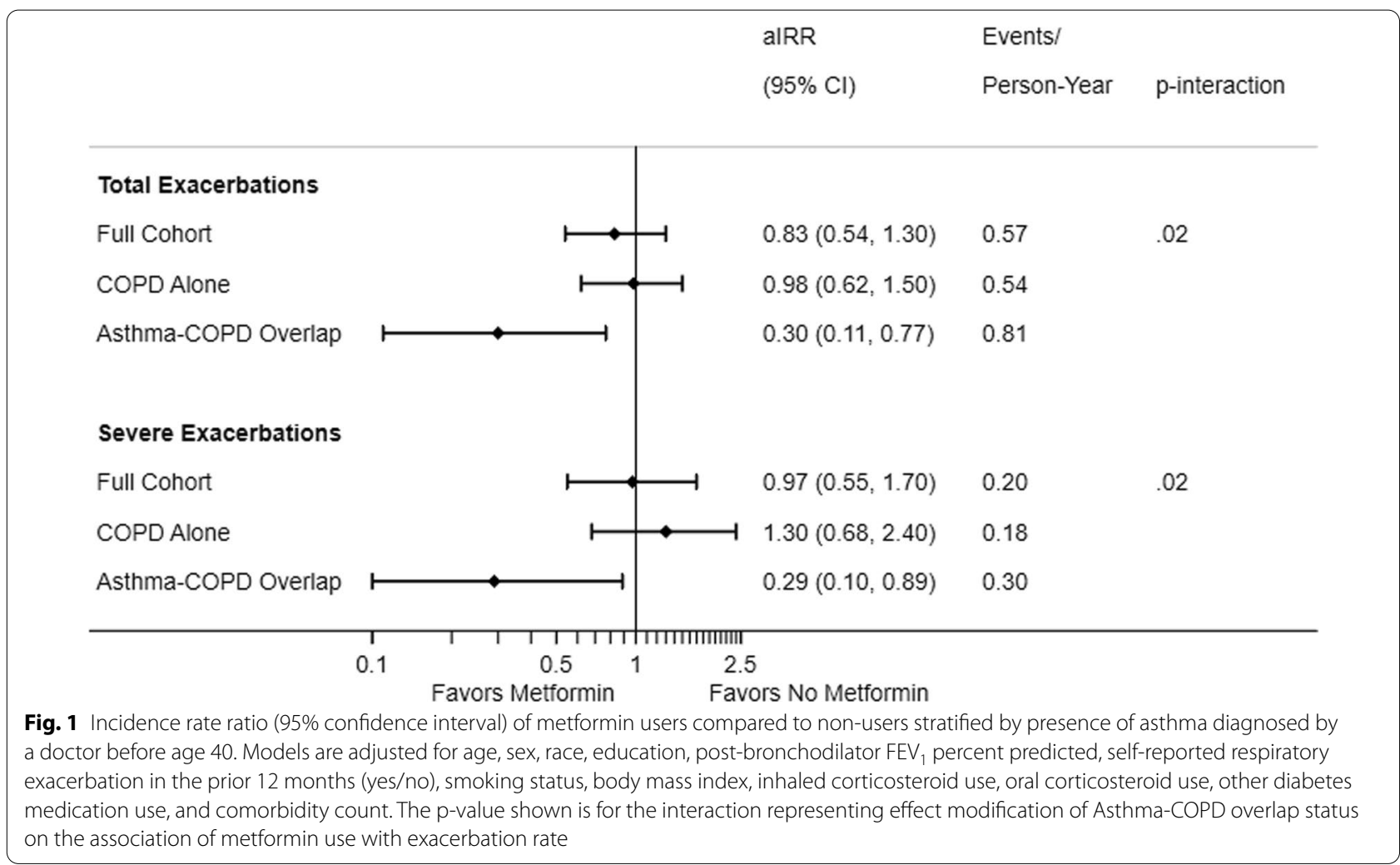

female, black, or obese, with more severe obstruction on spirometry, and more comorbidities. (Additional file 1: Table S1). There was no difference in the prevalence of ACO between metformin users and non-users.

\section{Prevalent metformin use and longitudinal respiratory exacerbations}

Over 25,448 person-years, 14,512 total and 5032 severe exacerbations were recorded with a mean (SD) total exacerbation rate of $0.64(1.1)$ and severe exacerbation rate of 0.24 (0.62). Participants with ACO had higher exacerbation rates compared to those with COPD alone. Metformin users were followed for an average of $6.5 \pm 2.5$ years (median 7.3 years, maximum 10.2 years), which was similar to the average $6.4 \pm 2.7$ years (median 7.4 years, maximum 10.4 years) among metformin nonusers (p-value 0.5). Overall, there was no association of metformin use and total exacerbations (adjusted incidence rate ratio [aIRR] 0.83 ; 95\% CI $0.54,1.3$ ) or severe exacerbations (aIRR 0.97; 95\% CI 0.55, 1.7). However, among participants with ACO, metformin use was associated with a lower rate of total exacerbations (aIRR 0.3 ; 95\% CI 0.11, 0.77) and severe exacerbations (aIRR 0.29 ; 95\% CI 0.1, 0.89). Among participants with COPD alone, metformin use was not associated with either outcome (Fig. 1). There was statistical evidence that the
ACO modified the association of metformin use and rate of exacerbations ( $p$-value for interaction $<0.05$ for both comparisons).

These results were not qualitatively different in sensitivity analyses utilizing alternative definitions of ACO (Additional file 1: Figure S2). Replacement of comorbidity count with individual comorbidities did not qualitatively change results (not shown).

\section{Prevalent metformin use and cross-sectional secondary outcomes}

Baseline cross-sectional associations between metformin use and SGRQ score, 6MWD, and FEV1pp are presented in Table 2. Among all participants, metformin use was associated with lower SGRQ score at baseline (adjusted mean difference $[\mathrm{aMD}]-2.7 ; 95 \% \mathrm{CI}-5.3,-0.2)$ which did not statistically differ between ACO and COPD (Table 2). Metformin use at baseline was not associated with differences in the rate of change for any secondary outcomes with no significant effect modification or subgroup effects by ACO status (Additional file 1: Table S2). A sensitivity analysis that included COPDGene participants who had not accrued follow-up time after the baseline visit revealed similar results (Additional file 1: Table S3). 
Table 2 Adjusted mean difference (95\% confidence interval) comparing metformin users to non-users for cross-sectional secondary outcomes

\begin{tabular}{|c|c|c|c|c|}
\hline \multirow[t]{2}{*}{ Outcome } & \multirow[t]{2}{*}{ All participants $(n=3969)$} & \multicolumn{3}{|l|}{ Subgroup analysis } \\
\hline & & Asthma-COPD overlap $(n=510)$ & COPD alone $(n=3459)$ & p-interaction \\
\hline $\begin{array}{l}\text { St. George respiratory questionnaire total } \\
\text { score }\end{array}$ & $-2.7(-5.3,-0.2)$ & $-4(-9.7,1.7)$ & $-2.5(-5.3,0.2)$ & 0.6 \\
\hline Six-Minute Walk Distance (ft) & $20(-29.7,69.7)$ & $-20.8(-133.9,92.3)$ & $26.5(-26.7,79.6)$ & 0.4 \\
\hline $\begin{array}{l}\text { Post-Bronchodilator FEV } 1 \text { percent pre- } \\
\text { dicted }\end{array}$ & $-0.77(-3.9,2.4)$ & $-3.6(-10.7,3.5)$ & $-0.16(-3.5,3.2)$ & 0.4 \\
\hline
\end{tabular}

Models are adjusted for age, sex, race, education, post-bronchodilator FEV 1 percent predicted (except where it is the outcome), self-reported respiratory exacerbation in the prior 12 months (yes/no), smoking status, body mass index, inhaled corticosteroid use, oral corticosteroid use, other diabetes medication use, and comorbidity count. The p-value shown is for the interaction representing effect modification of Asthma-COPD overlap status on the association of metformin use with the outcome of interest. Lower St. George Respiratory Questionnaire score, higher six-minute walk distance, and higher FEV 1 percent predicted favor metformin use. Bolded values are statistically significant at $\mathrm{p}<0.05$

\section{Metformin initiation and secondary outcomes}

Among 2188 individuals not using metformin at baseline who attended the phase 2 follow-up, 108 reported metformin use at follow-up and thus were considered to have initiated metformin. Compared to those who did not use metformin, metformin initiation was associated with improved SGRQ score only in the group with ACO $($ aMD -10.0 ; 95\% CI -18.7 , -1.2 ; p-interaction $=0.03$ ). There were no associations between metformin initiation and 6MWD or FEV1pp or between metformin initiation and SGRQ score among participants with COPD alone (Table 3).

\section{Discussion}

In this retrospective analysis of a large multi-center observational cohort study of COPD, metformin use was associated with a lower rate of respiratory exacerbations only among individuals with concurrent physician-diagnosed asthma. We further report that metformin initiation was associated with an improvement in quality of life preferentially among those with ACO. Taken together, these results suggest that metformin may have benefit in select individuals with COPD, presumably those that are driven by asthma-related pathophysiology. To our knowledge, this is the first report of this association.

Although there are no universally agreed-upon diagnostic criteria for ACO, the definition of asthma-COPD overlap used in this study is common and is the operative definition of ACO within COPDGene [10]. Specific treatment options for ACO are limited as major therapeutic trials of asthma and COPD commonly exclude participants with ACO [4]. Given individuals with ACO often report greater morbidity than those with COPD alone, increased attention to risk factors and treatment options for this condition is warranted.

Metformin is an oral medication used in the treatment of type 2 diabetes. Numerous effects have been described beyond improvements in insulin sensitivity and glucose tolerance [16], including amelioration of systemic and airway inflammation [17, 18]. Any potential mechanism of benefit for metformin in ACO is speculative. Metformin has been reported to inhibit airway smooth muscle (ASM) proliferation through AMPK-mediated inhibition of TGF- $\beta 1$ signalling [19], a pathway that has also been demonstrated to impair ASM bronchorelaxation in response to beta-agonists [20]. Metformin decreased eosinophilic airway inflammation in an allergic

Table 3 Adjusted mean difference (95\% confidence interval) in change of secondary outcomes from baseline to 5-year follow-up between metformin initiators and non-initiators

\begin{tabular}{|c|c|c|c|c|}
\hline \multirow[t]{2}{*}{ Outcome } & \multirow[t]{2}{*}{ All participants $(n=2188)$} & \multicolumn{3}{|l|}{ Subgroup analysis } \\
\hline & & Asthma-COPD overlap $(n=278)$ & $\operatorname{COPD}(n=1910)$ & p-interaction \\
\hline St. George respiratory questionnaire total score & $-1(-4.1,2.1)$ & $-10(-18.7,-1.2)$ & $0.27(-3,3.6)$ & 0.03 \\
\hline Six-Minute Walk Distance (ft) & $5.2(-64,74.4)$ & $-129.4(-337.7,79)$ & $23(-50.4,96.5)$ & 0.2 \\
\hline Post-Bronchodilator FEV 1 percent predicted & $1.4(-0.87,3.7)$ & $-1.1(-7.7,5.4)$ & $1.8(-0.68,4.3)$ & 0.4 \\
\hline
\end{tabular}

Models are adjusted for age, sex, race, education, post-bronchodilator FEV1 pp (time-varying, excluded for FEV1 pp outcome), smoking status (time-varying), body mass index (time varying), inhaled corticosteroid use (time-varying), oral corticosteroid use (time-varying), other diabetes medication use, comorbidity count. The p-value shown is for the three-way interaction between metformin use, time, and Asthma-COPD overlap status. Lower St. George Respiratory Questionnaire score, higher six-minute walk distance, and higher $\mathrm{FEV}_{1}$ percent predicted favor metformin use. Bolded values are statistically significant at $\mathrm{p}<0.05$ 
asthma model [5] and an obese asthma model [23]. In the latter study, metformin treatment was also associated with an increase in regulatory T-lymphocytes, which have been shown in a separate study to reduce airway inflammation and hyperresponsiveness when administered intratracheally [22]. Studies of asthma using administrative data, which have excluded the presence of COPD, have reported that metformin use is associated with less exacerbations [6]. These translational and epidemiologic studies of metformin in asthma, combined with conflicting reports regarding metformin in COPD $[8,24]$, are consistent with our findings of possible benefit in ACO but not COPD. As metformin initiation was also associated with an improvement in SGRQ among participants with ACO, our report also suggests that this medication may play a role in attenuating both the daily impact of asthma on symptoms and quality of life and on more severe forms of disease exacerbation. Because associations were maintained with mutual adjustment for other diabetes medications, it is also plausible that any potential benefit may be specific to metformin rather than to general effects on glycemic control or insulin sensitivity.

Importantly, our results increase confidence that these findings are not driven by a healthy user effect, whereby users of preventative medications such as metformin are also more likely to adhere to chronic medications such as controllers for asthma or COPD [21]. The magnitude of such an effect would not be expected to be significantly different between individuals with ACO and COPD alone.

We additionally note that, although we did not find a statistically significant association between metformin use and respiratory outcomes among individuals with COPD, the size of our confidence intervals does not preclude the potential for clinically meaningful benefit or harm. The significance of a lower SGRQ score among all users of metformin, without consistent results in longitudinal analyses or the primary outcome, is unknown.

This study had several limitations. Our definition of ACO is based on participant report. Data necessary to test other definitions was not universally collected at the baseline visit, such as peripheral eosinophilia or serum markers of atopy. Because COPDGene did not comprehensively assess metabolic parameters at baseline, we were also unable to adjust for concurrent glycemic control. Thus, we were unable to explore whether metformin may improve asthma through effects on blood glucose independent of other aspects of metabolic function, although this may be less likely as associations were identified with concurrent adjustment for other diabetes medications that would also improve glycemic control. It is additionally possible that metformin use may represent diabetes and poor glucose control rather than medication use per se. However, the directionality of such an association would be expected to be in the opposite direction [25]. Additionally, medication use was not prospectively validated against medication lists or prescribing records, and dosages of medications were not collected, precluding assessment of dose-response relationships. Finally, with respect to the metformin initiator analysis, the exact time that metformin was started after the baseline visit was not collected, and thus some exposed persontime may be misclassified, though such misclassification would be expected to be conservative. The lack of information regarding time of metformin initiation also precluded investigation of exacerbation rate among metformin initiators.

\section{Conclusion}

In conclusion, within a well-characterized observational cohort, we report a protective association between metformin use and respiratory outcomes preferentially in individuals with asthma-COPD overlap. These results support a potential role of metformin in select patients with concurrent COPD and asthma that warrants prospective investigation.

\section{Supplementary Information}

The online version contains supplementary material available at https://doi. org/10.1186/s12931-021-01658-3.

\begin{abstract}
Additional file 1: Table S1. Baseline characteristics of included participants by asthma-COPD overlap status ( $n=3969)$. Table S2. Adjusted mean difference (95\% confidence interval) in change of secondary outcomes from baseline to 5-year follow-up between metformin users and nonusers. Table S3. Adjusted mean difference (95\% confidence interval) comparing metformin users to non-users for cross-sectional secondary outcomes including participants without follow-up data. Figure S1. STROBE diagram of cohort derivation. Figure S2. Incidence rate ratio (95\% confidence interval) comparing metformin users to non-users for exacerbations stratified by alternative alternative asthma-COPD overlap (ACO) definitions ( $n=3969)$
\end{abstract}

\section{Abbreviations}

6MWD: Six-minute walk distance; ACO: Asthma-COPD overlap; ASM: Airway smooth muscle; alRR: Adjusted incidence rate ratio; aMD: Adjusted mean difference; BMI: Body mass index; COPD: Chronic obstructive pulmonary disease;

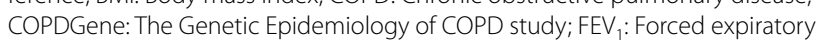
volume at $1 \mathrm{~s} ; \mathrm{FEV}_{1} \mathrm{pp}$ : Percent predicted forced expiratory volume at $1 \mathrm{~s}$; MCID: Minimal clinically important difference; SD: Standard deviation; SGRQ: St. George Respiratory Questionnaire.

\section{Acknowledgements}

Not applicable.

\section{Authors' contributions}

TDW, AF, GLK, and MCM made substantial contributions to the study design. AF performed the analysis. All authors made substantial contributions to the interpretation of data and revision of the manuscript. All authors read and approved the final manuscript. 


\section{Funding}

COPDGene is supported by the National Heart, Lung, and Blood Institute (U01HL89897 and U01HL089856) and by the COPD Foundation through contributions made to an Industry Advisory Board comprised of AstraZeneca, Boehringer-Ingelheim, Genentech, GlaxoSmithKline, Novartis, Pfizer, Siemens, and Sunovion. TDW is supported by the Department of Veterans Affairs, Veterans Health Administration, Office of Research and Development, Center for Innovations in Quality, Effectiveness and Safety (CIN 13-413). VT is supported by the National Heart, Lung, and Blood Institute (F32HL149258). MCM is supported by the National Institute of Environmental Health Sciences (P50ES018176), National Institute on Minority Health and Health Disparities (P50MD010431), and the United States Environmental Protection Agency (83615201 and 83615001). The content is solely the responsibility of the authors and does not necessarily represent the official views of the National Institutes of Health, the Department of Veterans Affairs, the Environmental Protection Agency, or the United States government.

\section{Availability of data and materials}

Study data are available upon reasonable request through COPDGene at https ://www.copdgene.org/.

\section{Ethics approval and consent to participate}

COPDGene was performed with local IRB authorization at all participating institutions. All participants gave written informed consent.

\section{Consent for publication}

\author{
Not applicable.
}

\section{Competing interests}

NNH reports grants from the COPD Foundation, grants and personal fees from AstraZeneca and GlaxoSmithKline, grants from Boehringer Ingelheim, and personal fees from Mylan, unrelated to the submitted work. MCM reports royalties from UpToDate and personal fees from Aridis, GlaxoSmithKline, and Celgene, unrelated to the submitted work. RAW reports personal fees from AstraZeneca, Contrafect, Roche-Genentech, Merck, Verona, Mylan, Theravance, AbbVie, GSK, ChemRx, Kiniksa, Bristol Myers Squibb, Galderma, Kamada, Pulmonx, Kinevant, PureTech, Arrowhead, VaxArt, and Polarean, unrelated to the submitted work. TDW, AF, GLK, JB, MN, VT, and NP report no competing interests.

\section{Author details \\ ${ }^{1}$ Section of Pulmonary, Critical Care, and Sleep Medicine, Baylor College ness and Safety, Michael E. DeBakey VA Medical Center, Houston, TX, USA. ${ }^{3}$ Division of Pulmonary and Critical Care Medicine, Johns Hopkins School of Medicine, 1830 E. Monument St. 5th Floor, Baltimore, MD 21205, USA. USA. ${ }^{5}$ Division of Pulmonary, Allergy, and Critical Care Medicine, Univer- sity of Pittsburgh, Pittsburgh, PA, USA. ${ }^{6}$ VA Pittsburgh Healthcare System, of Health, Bethesda, MD, USA. \\ Received: 29 December 2020 Accepted: 8 February 2021 Published online: 26 February 2021} of Medicine, Houston, TX, USA. ${ }^{2}$ Center for Innovations in Quality, Effective${ }^{4}$ Department of Epidemiology, Colorado School of Public Health, Aurora, CO, Pittsburgh, PA, USA. ${ }^{7}$ Department of Critical Care Medicine, National Institutes

\section{References}

1. Postma DS, Rabe KF. The asthma-COPD overlap syndrome. N Engl J Med. 2015;373(13):1241-9.

2. Bateman ED, Reddel HK, van Zyl-Smit RN, Agusti A. The asthma-COPD overlap syndrome: towards a revised taxonomy of chronic airways diseases? Lancet Respir Med. 2015;3(9):719-28. https://doi.org/10.1016/ S2213-2600(15)00254-4.

3. Global Initiative for Asthma. Diagnosis of diseases of chronic airflow limitation: asthma, COPD, and asthma-COPD overlap syndrome (ACOS). https://ginasthma.org/wp-content/uploads/2019/11/GINA_GOLD_ ACOS_2014-wms.pdf. Accessed 9 Oct 2020.

4. Sin DD, Miravitlles M, Mannino DM, et al. What is asthma-COPD overlap syndrome? Towards a consensus definition from a round table discussion. EurRespir J. 2016;48(3):664-73. https://doi.org/10.1183/13993003.00436 $-2016$.
5. Calixto MC, Lintomen L, André DM, et al. Metformin attenuates the exacerbation of the allergic eosinophilic inflammation in high fat-dietinduced obesity in mice. PLoS ONE. 2013;8(10):e76786. https://doi. org/10.1371/journal.pone.0076786.

6. Wu TD, Keet CA, Fawzy A, Segal JB, Brigham EP, McCormack MC. Association of metformin initiation and risk of asthma exacerbation: a claimsbased cohort study. Ann Am Thorac Soc. 2019. https://doi.org/10.1513/ AnnalsATS.201812-8970C.

7. Hitchings AW, Lai D, Jones PW, Baker EH. Metformin in severe exacerbations of chronic obstructive pulmonary disease: a randomised controlled trial. Thorax. 2016;71(7):587-93. https://doi.org/10.1136/thoraxjnl-2015208035.

8. Yen F-S, Wei JC-C, Yang Y-C, Hsu C-C, Hwu C-M. Respiratory outcomes of metformin use in patients with type 2 diabetes and chronic obstructive pulmonary disease. Sci Rep. 2020;10(1):10298. https://doi.org/10.1038/ s41598-020-67338-2.

9. Regan EA, Hokanson JE, Murphy JR, et al. Genetic epidemiology of COPD (COPDGene) study design. COPD. 2010;7(1):32-43. https://doi. org/10.3109/15412550903499522.

10. Hardin M, Cho M, McDonald M-L, et al. The clinical and genetic features of COPD-asthma overlap syndrome. EurRespir J. 2014;44(2):341-50. https ://doi.org/10.1183/09031936.00216013.

11 Jones PW, Quirk FH, Baveystock CM. The St George's respiratory questionnaire. Respir Med. 1991;85(Suppl B):25-31; discussion 33-37. https://doi. org/10.1016/s0954-6111(06)80166-6.

12. Jones PW. Interpreting thresholds for a clinically significant change in health status in asthma and COPD. EurRespir J. 2002;19(3):398-404. https ://doi.org/10.1183/09031936.02.00063702.

13. Holland AE, Spruit MA, Troosters T, et al. An official European Respiratory Society/American Thoracic Society technical standard: field walking tests in chronic respiratory disease. EurRespir J. 2014;44(6):1428-46. https://doi. org/10.1183/09031936.00150314.

14. Hankinson JL, Odencrantz JR, Fedan KB. Spirometric reference values from a sample of the general US population. Am J Respir Crit Care Med. 1999;159(1):179-87. https://doi.org/10.1164/ajrccm.159.1.9712108.

15. Putcha N, Puhan MA, Drummond MB, et al. A simplified score to quantify comorbidity in COPD. PLoS ONE. 2014. https://doi.org/10.1371/journ al.pone.0114438.

16. Hajjar J, Habra MA, Naing A. Metformin: an old drug with new potential. Expert OpinInvestig Drugs. 2013;22(12):1511-7. https://doi. org/10.1517/13543784.2013.833604.

17 Cameron AR, Morrison VL, Levin D, et al. Anti-inflammatory effects of metformin irrespective of diabetes status. Circ Res. 2016;119(5):652-65. https://doi.org/10.1161/CIRCRESAHA.116.308445.

18. Park CS, Bang B-R, Kwon H-S, et al. Metformin reduces airway inflammation and remodeling via activation of AMP-activated protein kinase. Biochem Pharmacol. 2012;84(12):1660-70. https://doi.org/10.1016/j. bcp.2012.09.025.

19. Pan Y, Liu L, Li S, et al. Activation of AMPK inhibits TGF- $\beta 1$-induced airway smooth muscle cells proliferation and its potential mechanisms. Sci Rep. 2018;8(1):3624. https://doi.org/10.1038/s41598-018-21812-0.

20. Ojiaku CA, Chung E, Parikh V, et al. Transforming growth factor- $\beta 1$ decreases $\beta 2$-agonist-induced relaxation in human airway smooth muscle. Am J Respir Cell Mol Biol. 2019;61(2):209-18. https://doi.org/10.1165/ rcmb.2018-03010C.

21. Shrank WH, Patrick AR, Alan BM. Healthy user and related biases in observational studies of preventive interventions: a primer for physicians. J Gen Intern Med. 2011;26(5):546-50. https://doi.org/10.1007/s1160 6-010-1609-1.

22. Joetham A, Takada K, Taube C, Miyahara N, Matsubara S, Koya T, Rha Y-H, Dakhama A, Gelfand EW. Naturally occurring lung CD4 CD25 T cell regulation of airway allergic responses depends on IL-10 induction of TGF- $\beta$. J Immunol. 2007;178(3):1433-42.

23. Guo Y, Shi J, Wang Q, Hong L, Chen M, Liu S, Yuan X, Jiang S. Metformin alleviates allergic airway inflammation and increases Treg cells in obese asthma. J Cell Mol Med. 2021;25(4):2279-84. https://doi.org/10.1111/ jcmm.16269.

24. Wang M-T, Lai J-H, Huang Y-L, Kuo F-C, Wang Y-H, Tsai C-L, Tu M-Y. Use of antidiabetic medications and risk of chronic obstructive pulmonary disease exacerbation requiring hospitalization: a disease risk score-matched nested case-control study. Respir Res 2020;21(1). 
25. Ho T-W, Huang C-T, Ruan S-Y, Tsai Y-J, Lai F, Yu C-J. Diabetes mellitus in patients with chronic obstructive pulmonary disease-the impact on mortality. PLoS ONE. 2017;12(4):e0175794.

\section{Publisher's Note}

Springer Nature remains neutral with regard to jurisdictional claims in published maps and institutional affiliations.
Ready to submit your research? Choose BMC and benefit from:

- fast, convenient online submission

- thorough peer review by experienced researchers in your field

- rapid publication on acceptance

- support for research data, including large and complex data types

- gold Open Access which fosters wider collaboration and increased citations

- maximum visibility for your research: over $100 \mathrm{M}$ website views per year

At BMC, research is always in progress.

Learn more biomedcentral.com/submissions 